\title{
A retrospective study of predictive factors for unexpectedly prolonged or shortened progression-free survival and overall survival among patients with metastatic renal cell carcinoma who received first-line targeted therapy
}

Sung Han Kim', Sohee Kim², Jungnam Joo ${ }^{2}$, Ho Kyung Seo ${ }^{1}$, Jae Young Joung ${ }^{1}$, Kang Hyun Lee ${ }^{1}$ and Jinsoo Chung ${ }^{1,3^{*}}$

\begin{abstract}
Background: To identify predictors of prolonged or shortened progression-free survival (PFS) and overall survival (OS) among patients with metastatic renal cell carcinoma (mRCC) who received first-line targeted therapies.

Methods: This retrospective study included 146 patients with mRCC who were treated during 2007-2015. These patients were divided into a group with the worst response (WG), an expected group (EG), and a group with the best response (BG), based on their PFS ( $\leq 3$ monthsnths, 3-18 monthsnths, and $>18$ monthsnths, respectively) and OS ( $<1$ year, 1-3 years, and $>3$ years, respectively). To identify significant predictive factors, the BG and WG were compared to the EG using the Memorial Sloan Kettering Cancer Center and Heng risk models.
\end{abstract}

Results: The overall PFS and OS were 9.3 months and 16.4 months, respectively. The median PFS for the WG (41.8\%), EG (45.9\%), and BG (12.3\%) were 2.7 months, 9.3 months, and 56.6 months, respectively, and the median OS for the WG (45.9\%), EG (35.6\%), and BG (18.5\%) were 5.5 months, 21.6 months, and 63.1 months, respectively; these outcomes were significantly different $(p<0.001)$. Nephrectomy (odds ratio [OR]: 7.15) was a significant predictor of PFS in the BG, and the significant predictors of OS in the BG were MSKCC intermediate risk (OR: 0.12), poor risk (OR: 0.04), and a diseasefree interval of $<1$ year (OR: 0.23) (all, $p<0.05$ ). Anemia (OR: 3.25) was a significant predictor of PFS in the WG, and the significant predictors of OS were age (OR: 1.05), anemia (OR: 4.13), lymphocytopenia (OR: 4.76), disease-free interval of $<1$ year (OR: 4.8), and synchronous metastasis (OR: 3.52) (all, $p<0.05$ ).

Conclusion: We identified several significant predictors of unexpectedly good and poor response to first-line targeted therapy among patients with mRCC.

Keywords: Renal cell carcinoma, Neoplasm metastasis, Prognosis, Overall survival, Progression free survival, Molecular targeted therapy

\footnotetext{
* Correspondence: cjs5225@ncc.re.kr

${ }^{1}$ Department of Urology, Center for Prostate Cancer, Hospital of National

Cancer Center National Cancer Center, Goyang, Korea

${ }^{3}$ Center for Prostate Cancer, National Cancer Center, 323 Ilsan-ro,

Ilsandong-gu, Goyang-si, Gyeonggi-do 410-769, Republic of Korea

Full list of author information is available at the end of the article
} 


\section{Background}

Research regarding the molecular biology of renal cell carcinoma (RCC) and the subsequent introduction of targeted therapeutic agents (TTs) have resulted in improved treatment guidelines for metastatic RCC (mRCC), and significantly improved progression-free survival (PFS) and overall survival (OS) [1, 2]. However, the appropriate treatment for mRCC in each case remains unclear, as the tumor's heterogeneity can affect the clinical outcomes after TT treatment, and it is difficult to accurately predict individual patients' prognoses. Therefore, it remains challenging to optimize therapeutic outcomes using personalized therapy.

Diverse criteria are used to stratify patients' prognoses, evaluate therapeutic responses, and determine patients' eligibility for TTs, and these criteria are used to help predict the patients' PFS and OS after TT treatment [3, 4]. Among the various evaluation tools and prognostic models, the RECIST criteria [5] are the best known and most commonly used evaluation tools for radiologically stratifying patients with solid tumors who received TT treatment, based on the responses of their primary tumor and metastatic lesions [4, 6]. Furthermore, the Memorial Sloan Kettering Cancer Center (MSKCC) [7, 8] and the International Metastatic Renal Cell Carcinoma Database Consortium (IMDC, also named as Heng) risk criteria [9] have been used in clinical prognostic models that predict the response to TT among patients with mRCC. However, even with these tools, clinicians may encounter difficulties in identifying patients who might experience clinical outcomes that significantly deviate from the expected outcomes. Therefore, the present study aimed to evaluate the clinicopathological characteristics of patients with $\mathrm{mRCC}$ who experience unexpectedly prolonged or shortened PFS and OS, and to identify significant predictors of unexpected clinical responses to first-line TTs.

\section{Methods}

This retrospective study was approved by the institutional review board of the Research Institute and Hospital National Cancer Center (approval no. NCC2014-0155), and the requirement for informed consent was waived. All patient data were anonymized and de-identified prior to our analysis. All study protocols were performed in accordance with the ethical tenets of the Declaration of Helsinki.

We identified 146 patients with $\mathrm{mRCC}$ and an intact contralateral kidney, who were treated using first-line TTs without any prior systemic treatment between January 2007 and April 2015. All included patients had complete follow-up and medical history data, and none of the patients discontinued their first-line TT due to Grade 3 or higher adverse events. The specific first-line TT was selected at the discretion of the treating urologist (JC), who considered each patient's histopathology, disease status, medical condition, and the wishes of the patient and their family after a comprehensive discussion regarding the anticipatory efficacy and adverse events of each TT. Each cycle of sunitinib consisted of a daily 50-mg oral dose over a 4-week period, which was followed by a 2-week hiatus. Each cycle of sorafenib consisted of twice-daily 400mg oral doses for a 6-week period. Each cycle of pazopanib consisted of a daily 800-mg oral dose over a 6-week period. Each cycle of temsirolimus consisted of a weekly 25-mg intravenous infusion over a 6-week period. All patients underwent a complete evaluation after every two cycles of TT, which included a total physical evaluation, blood tests, and radiological examinations. The radiological examinations included contrast-enhanced computed tomography and/or positron emission tomography-computed tomography and bone scans to evaluate treatment response, which was based on the RECIST criteria (version 1.1) [5]. Treatment was continued until disease progression was identified.

The 146 patients were grouped according to their PFS and OS, and the cut-offs were selected based on previously published representative findings that included a PFS of 4-18.8 months and an OS of 11.9-33.1 months $[1,2,10-12]$. Therefore, to stratify patients as having experienced unexpectedly prolonged or shortened OS and PFS, we categorized the patients using PFS cut-offs of 3 months and 18 months, and OS cut-offs of 1 year and 3 years. The upper PFS cut-off value was not set to 17 months, as none of the patients exhibited a PFS of approximately 17 months during their first-line TT treatment. Thus, the patients were grouped according to whether they had experienced the worst survival outcomes (WG; PFS: $\leq 3$ months, OS: $<1$ year), the normally expected outcomes (EG; PFS: 3-18 months, OS: 1-3 years), or the best survival outcomes (BG; PFS: $>18$ months, OS: $>3$ years).

Differences and associations between the baseline characteristics were examined using the chi-square test, Fisher's exact test, and the Kruskal-Wallis test, as appropriate. Binary logistic regression models were used to calculate the odds ratios (ORs) and $95 \%$ confidence intervals (CIs) for the factors that significantly affected the BG and WG outcomes, compared to the EG outcomes. Only factors with a $p$-value of $<0.10$ in the univariable analysis were subsequently evaluated in the multiple logistic regression analysis, using backwards stepwise selection with a significance level of 0.10 . Variables with large amounts of missing data (>20\% of patients) were excluded from the multivariable analysis (clinical $\mathrm{T}$ and $\mathrm{N}$ stages, and pathological $\mathrm{T}, \mathrm{N}$, and $M$ stages). The times to progression and death were evaluated using Kaplan-Meier curves and the logrank test. All analyses were performed using Stata software (version 13.1; Stata Corp., College Station, TX, USA), and differences with a $p$-value of $<0.05$ were considered statistically significant. 
Table 1 Clinicopathological characteristics of the worst group ( $n=61,41.8 \%$ ), expected group ( $n=67,45.9 \%)$, and the best group ( $n=18,12.3 \%)$, according to their progression-free survival

\begin{tabular}{|c|c|c|c|c|}
\hline Variables (N, \%) & Worst Group ( $\leq 3 \mathrm{mo})$ & Control Group (>3 and $\leq 18 \mathrm{mo}$ ) & Best Group (>18 mo) & $p$-value \\
\hline Age & $58.5 \pm 10.9$ & $58.0 \pm 11.2$ & $60.5 \pm 11.1$ & 0.697 \\
\hline Gender Male/Female & $45 / 1(73.8 / 26.2)$ & $55 / 12(82.1 / 37.7)$ & $17 / 1(94.4 / 5.6)$ & 0.140 \\
\hline Body mass index $\left(\mathrm{kg} / \mathrm{m}^{2}\right)$ & $23.4 \pm 3.1$ & $23.2 \pm 2.7$ & $23.9 \pm 2.0$ & 0.647 \\
\hline MSKCC criteria & & & & $<0.001$ \\
\hline Favorable & $3(5.9)$ & $5(9.3)$ & $6(37.5)$ & \\
\hline Intermediate & $30(58.8)$ & $42(77.8)$ & $10(62.5)$ & \\
\hline Poor & 18 (35.3) & $7(13.0)$ & 0 & \\
\hline Heng criteria & & & & 0.003 \\
\hline Favorable & $5(8.9)$ & $9(15.8)$ & $8(47.1)$ & \\
\hline Intermediate & $38(67.9)$ & $42(73.7)$ & $9(52.9)$ & \\
\hline Poor & $13(23.2)$ & $6(10.5)$ & 0 & \\
\hline ECOG 0 & $54(93.1)$ & $59(100)$ & $18(100)$ & 0.078 \\
\hline 1 & $4(6.9)$ & 0 & 0 & \\
\hline \multicolumn{5}{|l|}{ Metastatic site } \\
\hline Lung & $48(80.0)$ & $57(89.1)$ & $14(77.8)$ & 0.268 \\
\hline Liver & $15(25.0)$ & $9(14.8)$ & $1(5.9)$ & 0.139 \\
\hline Lymph node & $32(53.3)$ & $31(49.2)$ & $9(50.0)$ & 0.918 \\
\hline Bone & $19(32.2)$ & $21(34.4)$ & $6(35.3)$ & 0.968 \\
\hline Brain & $7(11.7)$ & $7(11.7)$ & $2(12.5)$ & 1.000 \\
\hline Other metastasis & $13(22.0)$ & $12(19.7)$ & $2(11.8)$ & 0.691 \\
\hline Nephrectomy & $28(45.9)$ & $35(52.2)$ & $16(88.9)$ & 0.004 \\
\hline Embolization & $3(4.9)$ & $3(4.5)$ & $2(11.1)$ & 0.455 \\
\hline Clinical T stage & & & & 0.371 \\
\hline $\mathrm{T} 1$ & $7(16.3)$ & $5(10.7)$ & $2(16.7)$ & \\
\hline $\mathrm{T} 2$ & $4(9.3)$ & $11(23.4)$ & 0 & \\
\hline T3 & $22(51.1)$ & $15(32.0)$ & $3(25.0)$ & \\
\hline $\mathrm{T} 4$ & $3(7.0)$ & $6(12.8)$ & $3(25.0)$ & \\
\hline Tx & $7(16.3)$ & $10(21.3)$ & $4(33.3)$ & \\
\hline N1 & $9(18.8)$ & $9(19.1)$ & $4(28.6)$ & 0.570 \\
\hline synchronous metastasis & $35(59.3)$ & $50(75.8)$ & $12(66.7)$ & 0.144 \\
\hline Fuhrman nuclear grade & & & & 0.767 \\
\hline $1-2$ & $14(34.1)$ & $8(36.7)$ & $3(25.0)$ & \\
\hline $3-5$ & $27(65.9)$ & $31(63.3)$ & $9(75.0)$ & \\
\hline Histology & & & & 0.701 \\
\hline Clear cell type & $45(77.6)$ & $55(87.3)$ & $11(73.3)$ & \\
\hline Non-clear cell type & $2(3.4)$ & $1(16)$ & 0 & \\
\hline Chromophobe with clear cell & $2(3.3)$ & $3(4.5)$ & $1(5.6)$ & \\
\hline Papillary with clear cell & $7(12.2)$ & $2(3.5)$ & $2(14.4)$ & \\
\hline unknown type & $2(3.4)$ & $2(3.2)$ & $1(6.7)$ & \\
\hline Sarcomatoid presence & $5(8.8)$ & $4(6.5)$ & $1(6.7)$ & 0.895 \\
\hline Treatment & & & & 0.877 \\
\hline Sunitinib & $43(70.5)$ & $45(67.2)$ & $13(72.2)$ & \\
\hline Sorafenib & $8(13.1)$ & $8(11.9)$ & $1(5.6)$ & \\
\hline
\end{tabular}


Table 1 Clinicopathological characteristics of the worst group ( $n=61,41.8 \%$ ), expected group ( $n=67,45.9 \%)$, and the best group ( $n=18,12.3 \%$ ), according to their progression-free survival (Continued)

\begin{tabular}{|c|c|c|c|c|}
\hline Pazopanib & $8(13.1)$ & 13(19.4) & $4(22.2)$ & \\
\hline Temsirolimus & $2(3.3)$ & $1(1.5)$ & 0 & \\
\hline RECIST response & & & & $<0.001$ \\
\hline$C R$ & 0 & $2(3.3)$ & $5(29.4)$ & \\
\hline$P R$ & $2(6.5)$ & $27(44.3)$ & $8(47.1)$ & \\
\hline SD & $7(22.6)$ & $23(37.7)$ & $3(17.6)$ & \\
\hline PD & $22(71.0)$ & $19(14.8)$ & $1(5.9)$ & \\
\hline \multicolumn{5}{|l|}{ Laboratory findings } \\
\hline Leukocytosis/Leucopenia & $15 / 0(26.3 / 0)$ & $8 / 3(13.8 / 5.2)$ & $2 / 1(11.8 / 5.9)$ & 0.140 \\
\hline Anemia & $43(75.4)$ & $28(48.3)$ & $5(29.4)$ & $<0.001$ \\
\hline Thrombocytosis/penia & $11 / 2(19.3 / 3.5)$ & $7 / 2(12.1 / 3.4)$ & $0 / 0$ & 0.279 \\
\hline Neutrophilia/penia & $14 / 0(24.6 / 0)$ & $7 / 1(12.1 / 1.7)$ & $1 / 1(5.9 / 5.9)$ & 0.089 \\
\hline Lymphocytosis/penia & 2/27 (3.5/47.4) & $5 / 14(8.6 / 24.1)$ & $1 / 1(5.9 / 5.9)$ & 0.004 \\
\hline Hyper/hypocalcemia & $3 / 11(5.3 / 19.3)$ & $3 / 3(5.2 / 5.2)$ & $0 / 0$ & 0.059 \\
\hline Hypoalbuminemia & $12(20.3)$ & 0 & 0 & $<0.001$ \\
\hline LDH elevated & $8(14.0)$ & $4(6.9)$ & 0 & 0.190 \\
\hline Neutrophil percent high/low & $113(19.3 / 5.3)$ & $5 / 7(8.6 / 12.1)$ & $1 / 5(5.9 / 29.4)$ & 0.046 \\
\hline Progression-free survival (mo.) & $2.7(0.1-3.0)$ & $9.3(3.3-16.5)$ & $56.6(18.3-68.4)$ & $<0.001$ \\
\hline Overall survival (mo.) & $6.9(0.3-58.4)$ & $18.6(4.0-70.3)$ & $68.3(18.3-78.4)$ & $<0.001$ \\
\hline
\end{tabular}

\section{Results}

The disease control rate, objective response rate, PFS, and OS among all 146 patients were $70.6 \%, 46.3 \%, 9.3$ months (95 \% CI: 7.3-11.2 months), and 16.4 months (95\% CI: 12.2-20.8 months), respectively. Seven patients (6.4\%) achieved complete response, 15 patients $(10.3 \%)$ were still being treated with first-line TT (i.e., stable disease or partial response), and 105 patients (71.9\%) exhibited a progression-free interval of $<1$ year. The baseline characteristics of the patients in the WG, EG, and BG are summarized in Tables 1 and 2. The median PFS for the WG $(n=$ 61, $41.8 \%)$, EG ( $n=67,45.9 \%)$, and BG ( $n=18,12.3 \%)$ were 2.7 months (95\% CI: 2.4-2.9 months), 9.3 months (95 \% CI: 8.3-11.1 months), and 56.6 months (95\% CI: 22.4-68.4 months), respectively (Fig. 1a). The median OS of the WG ( $n=65,45.9 \%)$, EG ( $n=52,35.6 \%)$, and BG ( $n$ $=27,18.5 \%$ ) were 5.5 months (95 \% CI: 4.5-6.9 months), 21.6 months (95 \% CI: 19.8-24.4 months), and 63.1 months (95\% CI: 44.3-75.4), respectively (Fig. 1b). These survival outcomes were significantly different (all, $p<0.001$ ).

The correlation and parametric trend tests for PFS and OS revealed that each group's PFS and OS were significantly correlated (Pearson' correlation coefficient: 0.6283, and non-parametric trend test, $p<0.001)$. The correlation percentages for the BG, EG, and WG were $50 \%(n=9$, PFS: $>18$ months, OS: $>3$ years), $49.3 \%$ ( $n=33$, PFS: $3-$ 18 months, OS: $1-3$ years $)$, and $72.1 \%(n=44$, PFS: $\leq 3$ months, OS: $<1$ year).
When we compared the BG and EG using the complete MSKCC risk evaluation, only nephrectomy (OR: 7.15, 95 \% CI: 1.43-35.67) was a significant predictor of PFS in the multivariate analysis $(p=0.016)$ (Table 3 , see also Additional file 1: Table S1). The significant predictors of OS were MSKCC intermediate risk (OR: 0.12, 95 \% CI: 0.003-0.049), MSKCC poor risk (OR: 0.04, 95 \% CI: 0.010.87 ), and a disease-free interval of $<1$ year (Heng, OR: 0.23, 95 \% CI: 0.07-0.73) (all, $p<0.05$ ) (Table 4, see also Additional file 1: Table S2).

When we compared the WG $(n=105)$ and EG $(n=113)$, the only significant predictor of PFS was anemia (MSKCC, OR: 3.25, 95 \% CI: 1.41-7.52; Heng, OR: 2.87, 95 \% CI: 1.23-6.66; both, $p<0.05$ ) (Table 5, see also Additional file 1: Table S3). The significant predictors of OS were age (MSKCC, OR: 1.05, 95 \% CI: 1.01-1.1), anemia (MSKCC, OR: 4.13, 95 \% CI: 1.44-11.8; Heng, OR: 4.61, 95 \% CI: 1.68-12.66), lymphocytopenia (MSKCC, OR: 4.76, 95 \% CI: 1.25-18.17; Heng, OR: 5.26, 95 \% CI: 1.44-19.14), a disease-free interval of $<1$ year (MSKCC, OR: $4.8,95 \% \mathrm{CI}$ : 1.1-20.9), and synchronous metastasis (MSKCC, OR: 3.52, $95 \%$ CI: 1.07-11.61) (all, $p<0.05$ ) (Table 6, see also Additional file 1: Table S4).

\section{Discussion}

The shift to TTs for treating mRCC has greatly improved the PFS of patients with mRCC. However, TTs are rarely curative and therapeutic resistance develops after 6-11 
Table 2 Clinicopathological characteristics of the worst group $(n=67,45.9 \%)$, expected group ( $n=5235.6 \%)$, and best group $(n=27,18.5 \%)$, according to their overall survival

\begin{tabular}{|c|c|c|c|c|}
\hline Variables (N, \%) & Worst Group (<1 y) & Control Group (1-3 y) & Best Group (>3 y) & $p$-value \\
\hline Age (years) & $60.5 \pm 10.7$ & $57.1 \pm 11.5$ & $56.3 \pm 10.3$ & 0.136 \\
\hline Gender (Male/Female) & $50 / 17(74.6 / 25.4)$ & $45 / 7(86.5 / 13.5)$ & $22 / 5(81.5 / 18.5)$ & 0.266 \\
\hline Body mass index $\left(\mathrm{kg} / \mathrm{m}^{2}\right)$ & $22.9 \pm 2.8$ & $23.7 \pm 2.5$ & $24.3 \pm 2.9$ & 0.096 \\
\hline MSKCC criteria & $59(88.1)$ & $43(100)$ & $19(73.1)$ & $<0.001$ \\
\hline Favorable risk & 0 & $4(9.3)$ & $10(52.6)$ & \\
\hline Intermediate risk & $39(66.1)$ & $34(79.1)$ & $9(47.4)$ & \\
\hline Poor risk & 20(33.9) & $5(11.6)$ & 0 & \\
\hline Heng criteria & $64(95.5)$ & $44(84.6)$ & $22(81.5)$ & $<0.001$ \\
\hline Favorable risk & $2(3.1)$ & $9(20.5)$ & $11(50.0)$ & \\
\hline Intermediate risk & $46(71.9)$ & $32(72.7)$ & $11(50.0)$ & \\
\hline Poor risk & $16(25.0)$ & $3(6.8)$ & 0 & \\
\hline ECOG 0 & $61(93.8)$ & $47(100)$ & $23(100)$ & 0.109 \\
\hline 1 & $4(6.2)$ & 0 & 0 & \\
\hline \multicolumn{5}{|l|}{ Metastatic site } \\
\hline Lung & $54(81.8)$ & $42(84.0$ & $23(88.5)$ & 0.738 \\
\hline Liver & 18(27.3) & $6(12.2)$ & $1(4.3)$ & 0.020 \\
\hline Lymph node & $33(49.3)$ & $17(36.2)$ & $8(33.3)$ & 0.064 \\
\hline Bone & $23(34.8)$ & $16(34.0)$ & $6(25.0)$ & 0.612 \\
\hline Brain & $9(13.6)$ & $5(10.6)$ & $2(8.3)$ & 0.758 \\
\hline Other metastasis & $18(27.3)$ & $5(10.6)$ & $4(16.7)$ & 0.083 \\
\hline $\begin{array}{l}\text { Nephrectomy } \\
\text { Embolization }\end{array}$ & $\begin{array}{l}23(34.3) \\
4(5.9)\end{array}$ & $\begin{array}{l}32(61.5) \\
1(1.9)\end{array}$ & $\begin{array}{l}24(88.9) \\
3(11.1)\end{array}$ & $<0.0010 .146$ \\
\hline Clinical T stage & $43(64.2)$ & $35(67.3)$ & & 0.179 \\
\hline $\mathrm{T} 1$ & $4(10.8)$ & $6(17.2)$ & $3(18.8)$ & \\
\hline $\mathrm{T} 2$ & $3(8.1)$ & $8(20.0)$ & $7(12.5)$ & \\
\hline $\mathrm{T} 3$ & $15(40.5)$ & $11(31.5)$ & $9(31.3)$ & \\
\hline $\mathrm{T} 4$ & $8(21.6)$ & $3(8.6)$ & $0(18.8)$ & \\
\hline$T x$ & $7(18.9)$ & $7(20.0)$ & $2(18.8)$ & \\
\hline N1 & $13(31.0)$ & $6(14.6)$ & $5(29.4)$ & 0.229 \\
\hline Synchronous metastasis & $58(87.9)$ & $31(60.8)$ & $8(30.8)$ & 0.001 \\
\hline Fuhrman nuclear grade & $41(61.2)$ & $39(75.0)$ & $22(81.5)$ & 0.460 \\
\hline $1-2$ & $13(31.7)$ & $12(30.8)$ & $10(45.5)$ & \\
\hline $3-5$ & $28(68.3)$ & $27(69.2)$ & $12(54.5)$ & \\
\hline Histology & $63(94.0)$ & $50(96.2)$ & $26(96.3)$ & 0.581 \\
\hline Clear cell type & $50(79.4)$ & $44(89.8)$ & $17(70.8)$ & \\
\hline Non-clear cell type & $2(3.2)$ & $1(2.0)$ & 0 & \\
\hline Chromophobe with clear cell & $2(3.0)$ & $2(3.8)$ & $2(7.4)$ & \\
\hline Papillary with clear cell & $7(6.5)$ & $1(2.3)$ & $3(5.1)$ & \\
\hline Unknown type & $2(3.2)$ & $1(2.0)$ & $2(8.3)$ & \\
\hline Sarcomatoid presence & $3(4.8$ & $1(2.0)$ & $2(8.3)$ & 0.168 \\
\hline Treatment & & & & 0.430 \\
\hline Sunitinib & $42(62.7)$ & $37(71.2)$ & $22(81.5)$ & \\
\hline Sorafenib & $9(13.4)$ & $6(11.5)$ & $2(7.4)$ & \\
\hline Pazopanib & $13(19.4)$ & $9(17.3)$ & $3(11.1)$ & \\
\hline
\end{tabular}


Table 2 Clinicopathological characteristics of the worst group $(n=67,45.9 \%)$, expected group $(n=5235.6 \%)$, and best group $(n=27,18.5 \%)$, according to their overall survival (Continued)

\begin{tabular}{|c|c|c|c|c|}
\hline Temsirolimus & $3(4.5)$ & 0 & 0 & \\
\hline RECIST response & & & & $<0.001$ \\
\hline$C R$ & 0 & $4(9.1)$ & $3(15.0)$ & \\
\hline$P R$ & $9(20.0)$ & $19(43.2)$ & $9(45.0)$ & \\
\hline SD & $11(24.4)$ & $14(31.8)$ & $8(40.0)$ & \\
\hline PD & $25(55.6)$ & $7(15.9)$ & 0 & \\
\hline \multicolumn{5}{|l|}{ Laboratory findings } \\
\hline Leukocytosis/Leucopenia & 19/1 (28.4/1.6) & $4 / 2(8.9 / 4.4)$ & $2 / 1(7.4 / 3.7)$ & 0.030 \\
\hline Anemia & $51(76.4)$ & $17(37.8)$ & $8(29.6)$ & $<0.001$ \\
\hline Thrombocytosis/penia & $14 / 2(20.9 / 3.0)$ & $4 / 2(8.9 / 4.4)$ & $0 / 0$ & 0.041 \\
\hline Neutrophilia/penia & 18/0 (26.9/0) & $2 / 1(4.4 / 2.2)$ & $2 / 1(7.4 / 3.7)$ & 0.002 \\
\hline Lymphocytosis/penia & $1 / 37(1.5 / 55.2)$ & 4/4 (8.9/8.9) & $3 / 1(11.1 / 3.7)$ & $<0.001$ \\
\hline Hyper/hypocalcemia & $5 / 11(7.4 / 16.4)$ & $1 / 2(2.2 / 4.4)$ & $0 / 1(0 / 3.7)$ & 0.077 \\
\hline Hypoalbuminemia & 12(17.9) & 0 & 0 & 0.002 \\
\hline LDH elevated & $10(14.9)$ & $2(4.4)$ & 0 & 0.051 \\
\hline Neutrophil percent high/low & $16 / 1(23.9 / 1.5)$ & 0/8(0/17.8) & $1 / 6(3.7 / 22.2)$ & $<0.001$ \\
\hline PFS (mo.) & $2.7(1-9.3)$ & $9.5(1-28.3)$ & $12.2(1-68.4)$ & $<0.001$ \\
\hline OS (mo.) & $5.5(0.3-11.6)$ & $21.6(12.1-35.7)$ & $63.1(36.6-88.4)$ & $<0.001$ \\
\hline
\end{tabular}

months of first-line TT treatment, which eventually leads to disease progression within 4-18.8 months; thus, only a few studies have reported significant improvements in OS $[1,2,10,11]$. However, the absence of any significant improvements in OS are mainly related to the confounding effects of crossover to active treatment from the placebo/ comparator arm. [13] Nevertheless, TT resistance and disease control are addressed via sequential therapy using various combinations of TTs, which provide a general OS of 11.9-33.1 months, and an OS of 9.0-10.9 months for patients with poor-risk features [9, 10, 12, 14, 15].

In the present study, we used PFS cut-off values of 3 months and 18 months, and OS cut-off values of 1 year and 3 years, in order to identify the patients that experienced unexpectedly prolonged or shortened survival outcomes $[1,2,10,12]$. The cut-off for unexpectedly prolonged PFS was selected based on a review of sorafenib and sunitinib by Porta et al. [13], and a study by Buchler et al. that reported a PFS of 17.7 months among patients who received sunitinib followed by sorafenib $(n=138)$, and 18.8 months among patients who received sorafenib followed by sunitinib $(n=122)$ [16]. Another review article [12] reported that a study of sorafenib from the Nexavar Charity Patient Aid Program provided a PFS of 17.6 months with a $95 \%$ disease control rate. The OS cut-off was supported by data from the SWITCH study, which reported an OS of 31.5 months for the sorafenib-sunitinib group and an OS of 30.2 months for the sunitinib-sorafenib group [17]. Furthermore, Tomita et al. reported that their first-line TT group $(n=25$, a median of six 6-week cycles) achieved an OS of 33.1 months, and their pretreated group $(n=26 ; 9.5$ cycles of TT) achieved an OS of 32.5 months [12]. Therefore, we compared the correlations between PFS and OS in each group, and found that these outcomes were well correlated. Interestingly, the WG exhibited the greatest correlation between PFS and OS (72.1\% of patients), while the BG and EG only exhibited correlations for $50 \%$ of their patients.

In the present study, the overall disease control rate (70.6\%), objective response rate (46.3\%), and median PFS (9.3 months, $95 \%$ CI: 7.3-11.2 months) were similar to those of other previously published series (69-79\%, 24-32 \%, and PFS: 5.5-11.1 months for first-line sunitinib $[11,18]$, sorafenib $[11,19,20]$, and pazopanib [21], respectively). In contrast, the median OS (16.4 months, $95 \%$ CI: 12.2-20.8 months) was shorter than those in previous TT trials (22.9-26.4 months) [10, 12, 13]. This discrepancy may be related to the fact that the previous studies generally included patients who had undergone nephrectomy and exhibited clear cell histology, while the present study included relatively small proportions of patients who had undergone nephrectomy (54.1\%), exhibited sarcomatoid histology (6.8\%), exhibited non-clear cell histology (18.4\%), or had poor- or unknown-risk features (30.0-34.2\%) according to the MSKCC and Heng criteria.

Our multivariate analyses revealed that nephrectomy (MSKCC, HR: 7.15) was the only significant predictor of PFS in the BG, and that anemia (MSKCC, HR: 3.25; Heng, HR: 2.87) was the only significant predictor of PFS in the 


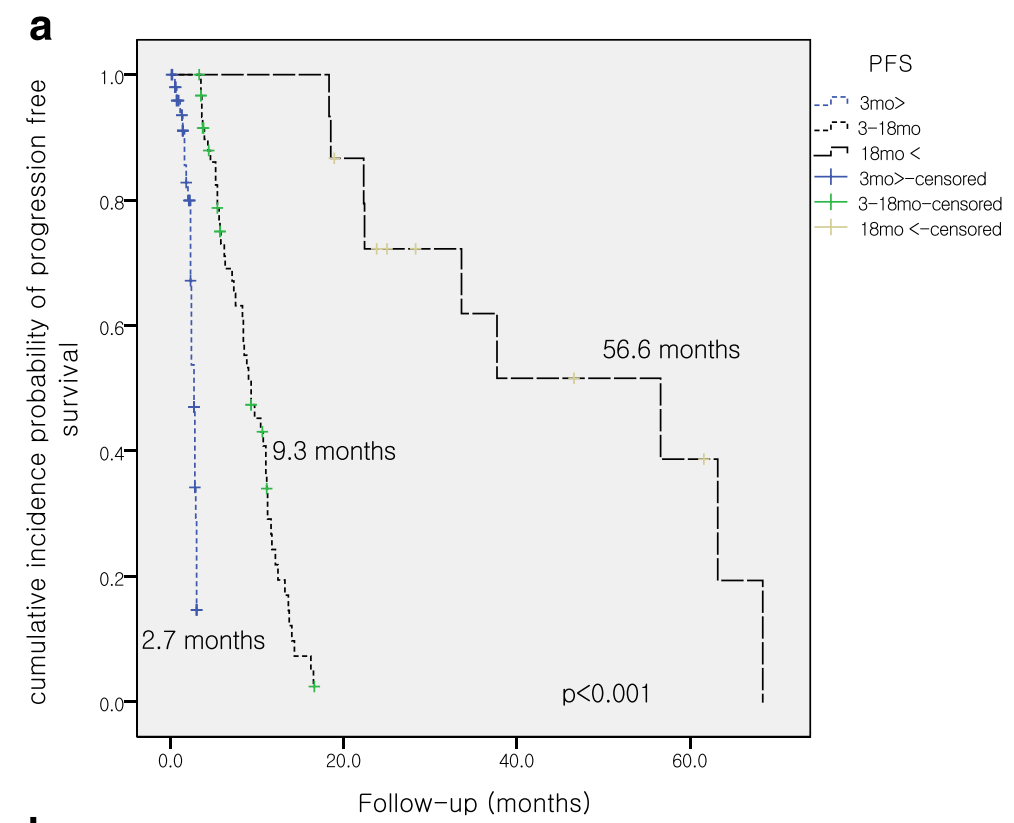

b

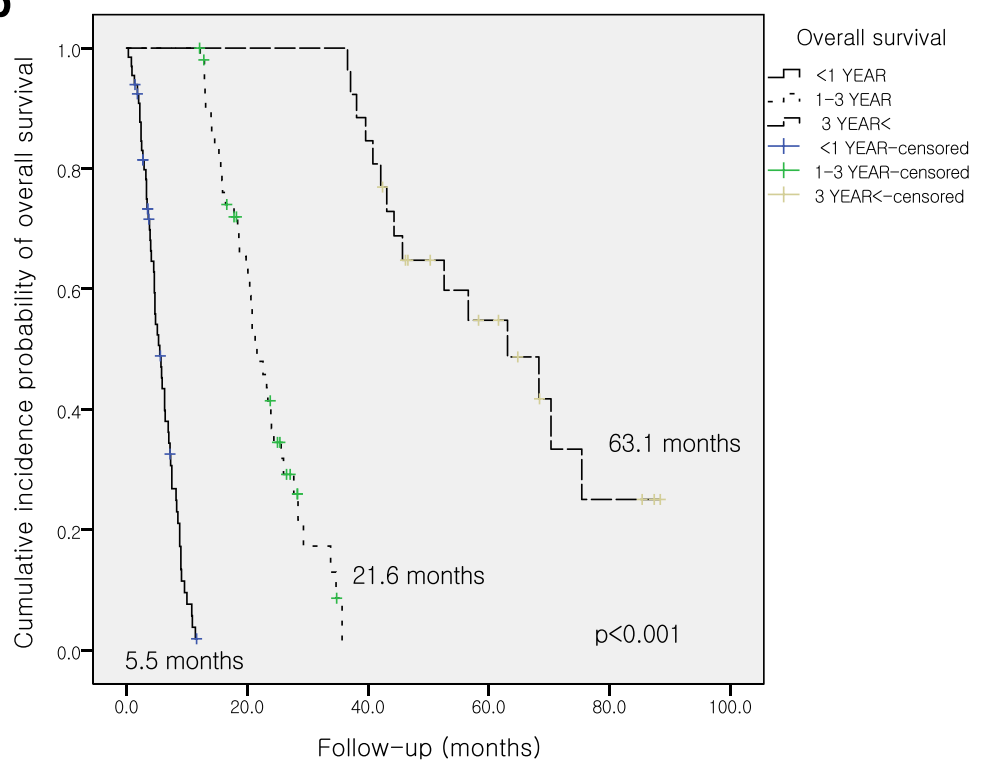

Fig. 1 The Kaplan-Meier curves for (a) progression-free survival (PFS) and (b) overall survival (OS) among the control group and the groups with the worst and best responses to first-line targeted therapy

Table 3 Predictive factors for progression-free survival after comparing the expected group and the group with the best response to therapy

\begin{tabular}{|c|c|c|c|c|c|c|c|c|c|}
\hline \multirow[b]{3}{*}{ Variables } & \multicolumn{3}{|c|}{ Univariate } & \multicolumn{6}{|c|}{ Multivariate } \\
\hline & \multirow[b]{2}{*}{ OR } & \multirow[b]{2}{*}{$P$-value } & \multirow[b]{2}{*}{$95 \% \mathrm{Cl}$} & \multicolumn{3}{|c|}{ MSKCC risk patients } & \multicolumn{3}{|c|}{ Heng risk patients } \\
\hline & & & & $\overline{\mathrm{HR}}$ & $P$-value & $95 \% \mathrm{Cl}$ & $\overline{\mathrm{HR}}$ & $P$-value & $95 \% \mathrm{Cl}$ \\
\hline Heng Intermediate risk group & 0.25 & 0.019 & $0.08-0.8$ & & & & 0.32 & 0.083 & $0.09-1.16$ \\
\hline Poor & 0.09 & 0.111 & $0.01-1.76$ & & & & 0.25 & 0.414 & $0.01-7.0$ \\
\hline $\mathrm{Nx}$ & 7.31 & 0.012 & $1.56-34.33$ & 7.15 & 0.016 & $1.43-35.67$ & 3.90 & 0.076 & $0.87-17.56$ \\
\hline
\end{tabular}


Table 4 Predictive factors for overall survival after comparing the expected group and the group with the best response to therapy

\begin{tabular}{|c|c|c|c|c|c|c|c|c|c|}
\hline \multirow[b]{3}{*}{ Variables } & \multicolumn{3}{|c|}{ Univariate } & \multicolumn{6}{|c|}{ Multivariate } \\
\hline & \multirow[b]{2}{*}{ OR } & \multirow[b]{2}{*}{$P$-value } & \multirow[b]{2}{*}{$95 \% \mathrm{Cl}$} & \multicolumn{3}{|c|}{ MSKCC risk patients } & \multicolumn{3}{|c|}{ Heng risk patients } \\
\hline & & & & $\mathrm{HR}$ & $P$-value & $95 \% \mathrm{Cl}$ & $\mathrm{HR}$ & $P$-value & $95 \% \mathrm{Cl}$ \\
\hline MSKCC Intermediate & 0.12 & 0.001 & $0.03-0.44$ & 0.12 & 0.003 & $0.03-0.49$ & & & \\
\hline Poor & 0.04 & 0.040 & $0.01-0.86$ & 0.04 & 0.041 & $0.01-0.87$ & & & \\
\hline $\mathrm{DFI}<1$ year & 0.22 & 0.003 & $0.08-176.29$ & & & & 0.23 & 0.013 & $0.07-0.73$ \\
\hline
\end{tabular}

WG (all, $p<0.05$ ). In this context, several retrospective studies have reported that nephrectomy provides benefits for PFS and OS in mRCC by reducing the tumor burden, although there is debate regarding whether this benefit is observed for all patients with mRCC. Thus, the results from two ongoing prospective randomized phase 3 studies may provide definitive data regarding nephrectomy's efficacy in $\mathrm{mRCC}$ that is treated using presurgical or postsurgical TT [22-24]. Nevertheless, the prognostic benefit of nephrectomy during the TT era has generally been positive, as it likely removes a large proportion of the tumor burden and facilitates better responses to TT. In the present study, we found that nephrectomy provided a benefit in $47.6 \%$ of BG patients with favorable-risk features, although this benefit was not significant in the multivariate analysis. In addition, anemia indicated a poor general condition that resembled paraneoplastic syndrome in $\mathrm{mRCC}$, although anemia is known to be a marker for poor inflammatory and immunerelated outcomes $[8,9,25]$. Furthermore, the Heng (or IMDC) prognostic model and the MSKCC model include anemia as a poor prognostic factor in their criteria for both PFS and OS [26].

The present study also revealed several significant negative prognostic markers for OS. In the WG, older age (HR: 1.05), decreased hemoglobin (HR: 4.13), lymphocytopenia (HR: 4.76), synchronous metastatic state (HR: 3.52), and a disease-free interval of $<1$ year were significantly associated with a reduced OS. In the BG, a disease-free interval of $<1$ year (HR: 0.23), the MSKCC intermediate-risk group (HR: 0.12), and the MSKCC poor-risk group (HR 0.004) were associated with a prolonged OS (all, $p<0.05$ ). Previous studies have reported that age is an important prognostic factor for localized RCC, as patients who exhibited late relapse and survival of $>5$ years beyond expectations were significantly younger, compared to patients who experience early relapse ( 3 months to 5 years after nephrectomy [27]. Furthermore, patients with RCC who are $<40$ years old generally have less aggressive tumor features and better survival outcomes [27-29]. Therefore, several studies have suggested that follow-up protocols for younger patients with RCC should be adjusted to include a longer follow-up, as these patients generally experience later relapse [27-29].

Similar to anemia, lymphocytopenia was associated with shortened OS in the present study. In this context, lymphocytes play key roles in tumor suppression, which include inducing cytotoxic cell death and the production of cytokines in cancer cells. Therefore, lymphocytopenia may indicate an impaired antitumor response, and explain the poor prognosis for patients with mRCC [30, 31]. However, the calcium was not significant prognostic factor in any comparisions among BG, WG vs. CG (Tables 3, 4 and 5). The reason for insignificant prognostic role of hypercalcemia like other Heng and MSKCC prognostic models was estimated by the small numbers of hypercalcemia in this study (4.1\%) similar to that of our previously publishing papers (9.4\%) with sunitinib study [32] that the hypercalcemia was not significant either.

In previous studies of various malignancies (including mRCC), the presence of synchronous or metachronous metastasis (based on the time between the diagnoses of the primary and secondary tumor) was a negative prognostic factor for OS. For example, Kwack et al. demonstrated that the time to metastasis and the number of metastases were important prognostic factors for mRCC during the immunotherapy era [29]. Furthermore, the International Metastatic Renal Cell Carcinoma Database

Table 5 Predictive factors for progression-free survival after comparing the expected group and the group with the worst response to therapy

\begin{tabular}{|c|c|c|c|c|c|c|c|c|c|}
\hline \multirow[b]{3}{*}{ Variables } & \multicolumn{3}{|c|}{ Univariate } & \multicolumn{6}{|c|}{ Multivariate } \\
\hline & \multirow[b]{2}{*}{ OR } & \multirow[b]{2}{*}{$P$-value } & \multirow[b]{2}{*}{$95 \% \mathrm{Cl}$} & \multicolumn{3}{|c|}{ MSKCC risk patients } & \multicolumn{3}{|c|}{ Heng risk patients } \\
\hline & & & & $\overline{\mathrm{HR}}$ & $P$-value & $95 \% \mathrm{Cl}$ & $\overline{\mathrm{HR}}$ & $P$-value & $95 \% \mathrm{Cl}$ \\
\hline Hemoglobin low & 3.29 & 0.003 & $1.49-7.27$ & 3.25 & 0.006 & $1.41-7.52$ & 2.87 & 0.014 & $1.23-6.66$ \\
\hline Platelet high & 1.75 & 0.288 & $0.62-4.91$ & & & & & & \\
\hline low & 1.11 & 0.916 & $0.15-8.24$ & & & & & & \\
\hline Lymphocyte high & 0.56 & 0.503 & $0.1-3.08$ & & & & 0.26 & 0.242 & $0.03-2.47$ \\
\hline Low & 2.69 & 0.016 & $1.2-6.02$ & & & & 2.05 & 0.098 & $0.88-4.78$ \\
\hline
\end{tabular}


Table 6 Predictive factors for overall survival after comparing the expected group and the group with the worst response to therapy

\begin{tabular}{|c|c|c|c|c|c|c|c|c|c|}
\hline \multirow[b]{3}{*}{ Variables } & \multicolumn{3}{|c|}{ Univariate } & \multicolumn{6}{|c|}{ Multivariate } \\
\hline & \multirow[b]{2}{*}{ OR } & \multirow[b]{2}{*}{$P$-value } & \multirow[b]{2}{*}{$95 \% \mathrm{Cl}$} & \multicolumn{3}{|c|}{ MSKCC risk patients } & \multicolumn{3}{|c|}{ Heng risk patients } \\
\hline & & & & $\mathrm{HR}$ & $P$-value & $95 \% \mathrm{Cl}$ & $\mathrm{HR}$ & $P$-value & $95 \% \mathrm{Cl}$ \\
\hline Age & 1.03 & 0.099 & $0.99-1.06$ & 1.05 & 0.045 & $1.01-1.10$ & & & \\
\hline Hemoglobin low & 6.46 & 0.000 & $2.74-15.22$ & 4.13 & 0.008 & $1.44-11.8$ & 4.61 & 0.003 & $1.68-12.66$ \\
\hline Lymphocyte high & 0.36 & 0.368 & $0.04-15.22$ & 0.22 & 0.215 & $0.02-2.42$ & 0.18 & 0.160 & $0.02-1.95$ \\
\hline Low & 13.16 & 0.000 & $4.18-9.34$ & 4.76 & 0.022 & $1.25-18.17$ & 5.26 & 0.012 & $1.44-19.14$ \\
\hline $\mathrm{DFI}<1$ year & 3.81 & 0.007 & $1.43-10.15$ & 4.80 & 0.036 & $1.10-20.9$ & & & \\
\hline synchronous metastasis & 4.68 & 0.001 & $1.85-11.84$ & 3.52 & 0.039 & $1.07-11.61$ & 3.17 & 0.057 & $0.97-10.41$ \\
\hline
\end{tabular}

Consortium also demonstrated that an increased metastatic tumor burden at the initial therapy was associated with worst OS among all patients with $\mathrm{mRCC}$, and that bone and liver metastases were more frequent in the groups with poor-risk features [26]. Although we did not observe significant differences in the baseline metastatic bone or liver lesions between the three groups, bone and liver metastases were more common in the WG (liver: $26.9 \%$, bone: $38.6 \%$ ), compared to the EG (liver: $12.2 \%$, bone: $34.0 \%$ ) and the BG (liver: $4.5 \%$, bone: $23.7 \%$ ) (all, $p>0.05$ ).

This study included several limitations that warrant consideration. First, the retrospective design and small sample size are prone to well-known biases, and larger prospective studies should be performed to validate our findings. Second, we did not perform any histological analyses, and additional analysis of RCC specimens from patients in the BG and WG might have provided histopathological data regarding prognostic biomarkers. Lastly, other existing clinical, political, and economic confounding factors influenced on the prognosis of $\mathrm{mRCC}$ during 8-year period of followup were not dealt in this study. The improving care system in nutritional, pain, and symptomatic therapeutic fields; introduction of new various curative and palliative strategies such as radiotherapy and metastatectomy, and widening coverage of insurance system on mRCC were the most affecting factors on improvement of prognoses in mRCC, which should be discussed in future studies. Nevertheless, our study identified several factors that were associated with unexpectedly prolonged or shortened survival outcomes after first-line TT treatment, by comparing the BG and WG to the EG. Our findings may provide clinicians with objective markers to identify candidates that are most and least likely to benefit from TTs. Furthermore, our findings may be useful for developing additional prognostic models or helping previous models to potentiate their accuracy of prognostic predictability and therapeutic plans that accurately predict patients' clinical outcomes in the TT era. For example, the nephrectomy, the presence of synchronous metastasis, age, and lymphocyte level might be also helpful in the MSKCC, Heng model to potentiate its predictability in mRCC treated with first line TT. This study comprised of $46 \%$ patients who had not received nephrectomy, whereas previous Heng criteria comprised of almost all nephrectomized patients that some discrepancies existed when evaluating the non-nephrectomized patients' prognoses. Therefore, some additionally useful information of non-nephrectomized patients' prognoses would be obtained in this study.

\section{Conclusion}

The present study identified several significant predictive factors that were associated with unexpectedly prolonged and shortened survival outcomes after first-line TT treatment in patients with $\mathrm{mRCC}$. However, a larger prospective study is needed to validate these factors.

\section{Additional file}

Additional file 1: Table S1. Predictive factors for progression-free survival after comparing the expected group and the group with the best response to therapy. Table S2. Predictive factors for overall survival after comparing the expected group and the group with the best response to therapy. Table S3. Predictive factors for progression-free survival after comparing the expected group and the group with the worst response to therapy. Table S4. Predictive factors for overall survival after comparing the expected group and the group with the worst response to therapy. (DOCX 49KB)

\section{Abbreviations}

$\mathrm{BG}$, the best responsive group; $\mathrm{Cl}$, confidence intervals; $\mathrm{EG}$, normal expected responsive group; $m R C C$, metastatic renal cell carcinoma; MSKCC, Memorial Sloan Kettering Cancer Center; OR, odds ratio; OS, overall survival; PFS, progression-free survival; $T$, target therapy; WG, the worst responsive group

\section{Acknowledgements \\ Ms. Jung Eun Kim and You-na Hwang from prostate cancer department contributed to the database management.}

Funding

The authors declare that they have no financial supports on this study.

\section{Availability of data and materials}

The dataset of this study was available on the Kidney cancer database of National Cancer Center, where the authors could freely receive the available database to use after the approval of our IRB committee under the consideration of the purpose of its use. The request for database was asked to the corresponding author (Dr. Jinsoo Chung, cjs5225@ncc.re.kr). 


\section{Authors' contributions}

SK, JJ carried out the statistical analysis in this study. HKS, JC, KHL, and JYJ carried the collecting samples and their data. JC, and SHK conceived of the study, and participated in its design and coordination and helped to draft the manuscript. All authors read and approved the final manuscript.

\section{Competing interests}

The authors declare that they have no competing interests.

\section{Consent for publication}

\section{Not applicable.}

The institutional review board of the Research Institute and Hospital National Cancer Center also waived the requirement of written consent from participants in this study. All the data were anonymized and de-identified abdout the participants prior to the analysis.

\section{Ethical approval and consent to participate}

This retrospective study was approved by the institutional review board of the Research Institute and Hospital National Cancer Center (approval no. NCC2014-0155), and the requirement for informed consent to participate in this study was waived due to its retrospective design. All patient data were anonymized and de-identified prior to the analysis. All study protocols were performed in accordance with the ethical tenets of the Declaration of Helsinki.

\section{Author details}

${ }^{1}$ Department of Urology, Center for Prostate Cancer, Hospital of National Cancer Center National Cancer Center, Goyang, Korea. ${ }^{2}$ Biometric Research Branch, Clinical Research Coordination Center, Hospital of National Cancer Center National Cancer Center, Goyang, Korea. ${ }^{3}$ Center for Prostate Cancer, National Cancer Center, 323 Ilsan-ro, Ilsandong-gu, Goyang-si, Gyeonggi-do 410-769, Republic of Korea.

\section{Received: 19 January 2016 Accepted: 25 July 2016 Published online: 02 August 2016}

\section{References}

1. Choudhury AD, Eeles R, Freedland SJ, Isaacs WB, Pomerantz MM, Schalken JA, Tammela TL, Visakorpi T. The role of genetic markers in the management of prostate cancer. Eur Urol. 2012;62(4):577-87.

2. Pecuchet $N$, Fournier $L S$, Oudard S. New insights into the management of renal cell cancer. Oncology. 2013;84(1):22-31.

3. Heng DY, Xie W, Regan MM, Harshman LC, Bjarnason GA, Vaishampayan UN, Mackenzie M, Wood L, Donskov F, Tan MH, et al. External validation and comparison with other models of the International Metastatic Renal-Cell Carcinoma Database Consortium prognostic model: a population-based study. Lancet Oncol. 2013;14(2):141-8.

4. Julka PK, Doval DC, Gupta S, Rath GK. Response assessment in solid tumours: a comparison of WHO, SWOG and RECIST guidelines. $\mathrm{Br}$ J Radiol. 2008;81(966):444-9.

5. Eisenhauer EA, Therasse P, Bogaerts J, Schwartz LH, Sargent D, Ford R, Dancey J, Arbuck S, Gwyther S, Mooney M, et al. New response evaluation criteria in solid tumours: revised RECIST guideline (version 1.1). Eur J Cancer. 2009;45(2):228-47.

6. Leon L, Garcia-Figueiras R, Suarez C, Arjonilla A, Puente J, Vargas B, Mendez Vidal MJ, Sebastia C. Recommendations for the clinical and radiological evaluation of response to treatment in metastatic renal cell cancer. Target Oncol. 2014;9(1):9-24.

7. Motzer RJ, Bacik J, Murphy BA, Russo P, Mazumdar M. Interferon-alfa as a comparative treatment for clinical trials of new therapies against advanced renal cell carcinoma. J Clin Oncol Off J Am Soc Clin Oncol. 2002;20(1):289-96.

8. Motzer RJ, Bacik J, Schwartz LH, Reuter V, Russo P, Marion S, Mazumdar M. Prognostic factors for survival in previously treated patients with metastatic renal cell carcinoma. J Clin Oncol Off J Am Soc Clin Oncol. 2004;22(3):454-63.

9. Heng DY, Xie W, Regan MM, Warren MA, Golshayan AR, Sahi C, Eigl BJ, Ruether JD, Cheng T, North S, et al. Prognostic factors for overall survival in patients with metastatic renal cell carcinoma treated with vascular endothelial growth factor-targeted agents: results from a large, multicenter study. J Clin Oncol Off J Am Soc Clin Oncol. 2009;27(34):5794-9.

10. Cho IC, Chung J. Current status of targeted therapy for advanced renal cell carcinoma. Korean J Urology. 2012;53(4):217-28.

11. Park SJ, Lee JL, Park I, Park K, Ahn Y, Ahn JH, Lee DH, Ahn S, Song C, Hong $\mathrm{JH}$, et al. Comparative efficacy of sunitinib versus sorafenib as first-line treatment for patients with metastatic renal cell carcinoma. Chemotherapy. 2012;58(6):468-74

12. Ye D, Eto M, Chung JS, Kimura G, Chang WC, Chang YH, Pang ST, Lee JL, Niu Y, Gurney $H$, et al. Use of targeted therapies for advanced renal cell carcinoma in the Asia-Pacific region: opinion statement from China, Japan, Taiwan, Korea, and Australia. Clin Genitourin Cancer. 2014;12(4):225-33.

13. Porta C, Tortora G, Linassier C, Papazisis K, Awada A, Berthold D, Maroto JP, Powles T, De Santis M. Maximising the duration of disease control in metastatic renal cell carcinoma with targeted agents: an expert agreement. Med Oncol. 2012;29(3):1896-907

14. Choueiri TK, Rini B, Garcia JA, Baz RC, Abou-Jawde RM, Thakkar SG, Elson P, Mekhail TM, Zhou M, Bukowski RM. Prognostic factors associated with longterm survival in previously untreated metastatic renal cell carcinoma. Annals Oncol. 2007;18(2):249-55.

15. De Lichtenberg TH, Hermann GG, Rorth M, Hojer Larsen MJ, Mansourvar Z Holm ML, Scheike T. Overall survival after immunotherapy, tyrosine kinase inhibitors and surgery in treatment of metastatic renal cell cancer: outcome of 143 consecutive patients from a single centre. Scand J Urol Nephrol. 2014:48(4):379-86.

16. Buchler T, Klapka R, Melichar B, Brabec P, Dusek L, Vyzula R, Abrahamova J. Sunitinib followed by sorafenib or vice versa for metastatic renal cell carcinoma-data from the Czech registry. Annals Oncol. 2012;23(2):395-401.

17. Eichelberg C, Vervenne WL, De Santis M, Fischer Von Weikersthal L, Goebell PJ, Lerchenmuller C, Zimmermann U, Bos MM, Freier W, Schirrmacher-Memme S, et al. SWITCH: A Randomised, Sequential, Open-label Study to Evaluate the Efficacy and Safety of Sorafenib-sunitinib Versus Sunitinib-sorafenib in the Treatment of Metastatic Renal Cell Cancer. Eur Urol. 2015;68(5):837-47.

18. Motzer RJ, Hutson TE, Tomczak P, Michaelson MD, Bukowski RM, Oudard S, Negrier S, Szczylik C, Pili R, Bjarnason GA, et al. Overall survival and updated results for sunitinib compared with interferon alfa in patients with metastatic renal cell carcinoma. J Clin Oncol Off J Am Soc Clin Oncol. 2009;27(22):3584-90.

19. Escudier B, Eisen T, Stadler WM, Szczylik C, Oudard S, Siebels M, Negrier S, Chevreau C, Solska E, Desai AA, et al. Sorafenib in advanced clear-cell renalcell carcinoma. N Engl J Med. 2007;356(2):125-34.

20. Escudier B, Szczylik C, Hutson TE, Demkow T, Staehler M, Rolland F, Negrier S, Laferriere N, Scheuring UJ, Cella D, et al. Randomized phase II trial of first-line treatment with sorafenib versus interferon Alfa-2a in patients with metastatic renal cell carcinoma. J Clin Oncol Off J Am Soc Clin Oncol. 2009: 27(8):1280-9.

21. Sternberg CN, Hawkins RE, Wagstaff J, Salman P, Mardiak J, Barrios CH, Zarba JJ, Gladkov OA, Lee E, Szczylik C, et al. A randomised, double-blind phase III study of pazopanib in patients with advanced and/or metastatic renal cell carcinoma: final overall survival results and safety update. Eur J Cancer. 2013;49(6):1287-96.

22. Mathieu R, Pignot G, Ingles A, Crepel M, Bigot P, Bernhard JC, Joly F, Guy L, Ravaud A, Azzouzi AR, et al. Nephrectomy improves overall survival in patients with metastatic renal cell carcinoma in cases of favorable MSKCC or ECOG prognostic features. Urol Oncol. 2015;33(8):339. e339-339 e315.

23. Shinohara N, Abe T. Prognostic factors and risk classifications for patients with metastatic renal cell carcinoma. Int J Urol. 2015;22(10):888-97.

24. Procopio G, Testa I, Verzoni E, lacovelli R, Grassi P, Galli G, De Braud F, Saravia D, Salvioni R. Time from nephrectomy as a prognostic factor in metastatic renal cell carcinoma patients receiving targeted therapies: overall results from a large cohort of patients. Oncology. 2015;88(3):133-8.

25. Santoni M, Buti S, Conti A, Porta C, Procopio G, Sternberg CN, Bracarda S, Basso U, De Giorgi U, Rizzo M, et al. Prognostic significance of host immune status in patients with late relapsing renal cell carcinoma treated with targeted therapy. Target Oncol. 2015;10(4):517-22

26. Ueda T, Uemura H, Tomita Y, Tsukamoto T, Kanayama H, Shinohara N, Tarazi J, Chen C, Kim S, Ozono S, et al. Efficacy and safety of axitinib versus sorafenib in metastatic renal cell carcinoma: subgroup analysis of Japanese patients from the global randomized Phase 3 AXIS trial. Jpn J Clin Oncol. 2013:43(6):616-28.

27. Hutson TE, Escudier B, Esteban E, Bjarnason GA, Lim HY, Pittman KB, Senico $P$, Niethammer A, Lu DR, Hariharan S, et al. Randomized phase III trial of temsirolimus versus sorafenib as second-line therapy after sunitinib in patients with metastatic renal cell carcinoma. J Clin Oncol Off J Am Soc Clin Oncol. 2014;32(8):760-7.

28. Kroeger N, Choueiri TK, Lee JL, Bjarnason GA, Knox JJ, MacKenzie MJ, Wood L, Srinivas S, Vaishamayan UN, Rha SY, et al. Survival outcome and treatment response of patients with late relapse from renal cell carcinoma in the era of targeted therapy. Eur Urol. 2014;65(6):1086-92. 
29. Kwak C, Park YH, Jeong CW, Jeong H, Lee SE, Ku JH. Characteristics of metastasis as a prognostic factor for immunotherapy in metastatic renal cell carcinoma. Tumori. 2007;93(1):68-74.

30. Keizman D, Ish-Shalom M, Huang P, Eisenberger MA, Pili R, Hammers $H$, Carducci MA. The association of pre-treatment neutrophil to lymphocyte ratio with response rate, progression free survival and overall survival of patients treated with sunitinib for metastatic renal cell carcinoma. Eur J Cancer. 2012;48(2):202-8.

31. Santoni M, De Giorgi U, lacovelli R, Conti A, Burattini L, Rossi L, Luca Burgio S, Berardi R, Muzzonigro G, Cortesi E, et al. Pre-treatment neutrophil-to-lymphocyte ratio may be associated with the outcome in patients treated with everolimus for metastatic renal cell carcinoma. Br J Cancer. 2013;109(7):1755-9.

32. Kwon WA, Cho IC, Yu A, Nam BH, Joung JY, Seo HK, Lee KH, Chung J. Validation of the MSKCC and Heng risk criteria models for predicting survival in patients with metastatic renal cell carcinoma treated with sunitinib. Ann Surg Oncol. 2013;20(13):4397-40.

\section{Submit your next manuscript to BioMed Central and we will help you at every step:}

- We accept pre-submission inquiries

- Our selector tool helps you to find the most relevant journal

- We provide round the clock customer support

- Convenient online submission

- Thorough peer review

- Inclusion in PubMed and all major indexing services

- Maximum visibility for your research

Submit your manuscript at www.biomedcentral.com/submit 